\title{
Negation of the Object in Sesotho
}

\author{
Elias Nyefolo Malete *
}

\begin{abstract}
This article examines constituent negation in Sesotho. It investigates negation of the object argument in clauses with non-copulative verbs. In the case of non-copulative verbs, transitive and di-transitive constructions will be considered. The article argues that Sesotho does not have a direct means of negating clausal constituents but employs clauses such as cleft sentences and clauses with AGRS [ho] as well as contrastive clauses to effect negation. It further examines negation in terms of Haegeman's (1995) Neg-Criterion, the well-formedness condition that determines the distribution and interpretation of negative elements. It gives a brief overview of grammatical concepts regarding negation and the notion object argument in its focus and post verbal positions, and explains how constituent negation, [the object argument] is realized in Sesotho.
\end{abstract}

Keywords: negation, object, Sesotho

\section{Introduction}

Negation as described by Zanuttini (1997) is a syntactic process whereby a language employs negative markers to negate a clause. Haegeman (1995) defines negation in terms of Neg-Criterion, the well-formedness condition that determines the distribution and interpretation of negative elements. This criterion asserts that a negative operator must be in a spec-head configuration with a negative head. Based on the Neg-Criterion, negative sentences are constructions which minimally have a negative feature, associated with a functional head of the extended projection of the verb. This implies that negative elements are identified as Negative Phrase headed by a negative head, where the head is in geometrical position with its specifier. In Sesotho the negative phrase will have negative morphemes /ha/, /sa/ and /se/ as heads.

Negation is further distinguished into sentence negation and constituent negation. According to Klima (1964), sentence negation is realized when negative pre-verbal particles are present in the sentence. Haegeman (1995) goes on to state that negative constituents that trigger subject inversion, have sentential scope and are referred to as

\footnotetext{
* Elias Nyefolo Malete: Department of African Languages, University of the Free State - Qwaqwa Campus,Private Bag X 13, Phuthaditjhaba, 9866. South Africa. Tel. 058718 5087, Fax. 0587185100 , maleteen@qwa.uovs.ac.za.
} 
negative operators. Negative operators express sentential negation. With regard to constituent negation, Haegeman (1995) states that preposed negative constituents that do not trigger subject inversion do not have sentential scope but constitute local negation, and they are referred to as non-negative operators. They are constituents such as "Not long after, not long ago" and such constituents do not qualify as operators because perculation in referential prepositional phrases is not available. Negation is restricted to a lower projection which is the adverb of time "long". Klima (1964) describes constituent negation as characterized by the use of negative affixes such as /un-/, where the negative particle is treated as part of certain constituents as in "unhappy". Constituent negation is also explained by Laka (1974) in terms of the Determiner Theory, which stipulates that the particle /not/is generated on noun phrases and adverbs as demonstrated in (1) below:

(1) a. [ Not many] people arrived

b. [No man] will eat another

In (1) above, the scope of negation is restricted to the adverb "many" and the noun phrase "man", a grammatical process referred to as constituent or local negation by Klima (1964), Haegeman (1995) and Laka (1974). In Sesotho however, constituent negation and in particular, negation of the NP object is achieved through a different grammatical process as it will observed in this study. It will however be necessary to define and look at the general characteristics of the NP object as a syntactical category.

\section{The notion object}

Anderson (1984) defines an object as a noun or pronoun denoting a person or a thing affected by the action expressed by the verb, where a verb becomes transitive because its action goes over to an object. The notion object also refers to that NP which is immediately dominated by VP. Anderson (1984) goes on to state that objects are a variable subset of the non-subjective absolute phrases and there may be more than one object in a simple sentence. According to Moravcsik (1984), objects refer to some controlling participants of a two-participant event that constitutes in its entirety the primary target for the event.

According to Collinge (1984), objects are identified through their categorical operators, semantic diagnostics and control properties. With regard to categorial operations, an NP is a simple operand noun and it can be placed in second highest position. They can be controlled by three semantic features such as definiteness, affectedness and animacy, and control properties are considered to be accessibility, omission and deletion.

Moravcsik (1984) argues that direct objects have features that are general NP properties. These general properties include internal composition, head constituent relations and pragmatic function. In the case of internal composition, the head of a direct object NP may be a noun, adjective, quantifier, pronoun, infinitive or a clause. An object phrase with a 


\section{Negation of the Object in Sesotho}

nominal head can accommodate a wider range of satellites such as determiners and quantifiers. Objects may also be represented by pronominals. With regard to constituent relations, Moravcsik (1984) maintains that the semantic relation between verbs and objects is a head - modifier relation in that the verb - object construction is a subtype of the predicate expressed by the verb itself, where there is a unidirectional relation between the verb and the object, e.g. a verb may require the presence of an object complement for semantic - syntactic well-formedness. Finally, objects may take basic pragmatic functions of topic, focus and pragmatic neutrality. NP objects are however unique NP's on the basis of specific argument function they fulfill, coupled with association with a particular case marker.

On the other hand, Gil (1984) stipulates specific characteristic properties of direct objects in a basic sentence:

a) NP object must have a thematic role property of patienthood.

b) An NP object should have pragmatic reference property of lesser referential strength, i.e. direct objects are of low referentiality, they occur at the bottom of a grammatical relation quantifier scope hierarchy.

c) An NP object must have pragmatic reference property of indefiniteness. Direct object position is a preferred position for introducing indefinite arguments. According to Lazard (1984), nominal categories of objects are variations such as humanness or animacy and definiteness. There are three grammatical persons which are not logically symmetrical, viz. third person may be anybody or anything but mostly non-human, first and second persons rank higher in the hierarchy of humanness and are mostly human.

d) Direct objects occur to the right of subjects in the basic word order of almost all languages. In other languages, the relative word order of the NP's in a clause is quite free.

e) Direct objects must have a clausal property of transitivity, which serves as a diagnostic for direct-objecthood, since the presence of a direct object is a characteristic feature of transitive clauses.

With regard to the structural position of the object and case licensing, Haegeman (1995) states that there is an agreement projection responsible for checking agreement features and accusative case of the object which is AgrOP. The agreement features of objects are licensed at LF if the features are weak and before spell out if they are strong. The object argument has two structural positions; viz. the base position within the VP where it obtains its theta-role and the derived object position above the VP, the [Spec, AgrOP], the landing site of the object after movement responsible for accusative case licensing. According to Ouhalla (1999), accusative case is assigned under Spec-head agreement with a complex 
[Agr0 [V] Agr0].

The idea of a two structural object position can be clearly illustrated by a transitive Sesotho sentence as adopted by Du Plessis (1995) for African languages as shown in (2) and the diagram in (1) below.
(2) Ngwana
o
bala buka
The child she/he
reads a book
[ The child reads a book ]

Diagram 1. Sesotho Transitive Sentence

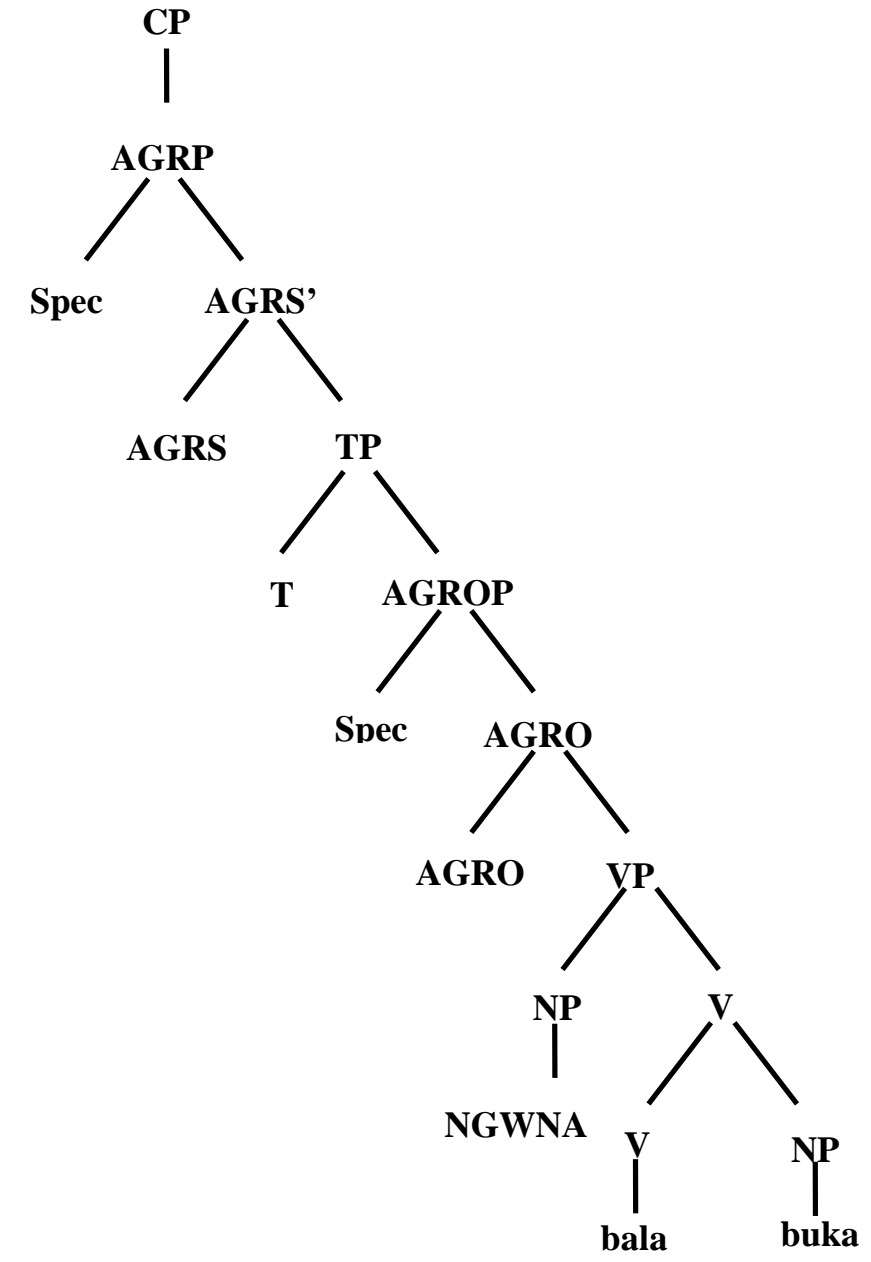

According to the structure in (1) above, the NP object [buka] originates within the VP. The subject [ngwana] is raised to [Spec, AgrSP] for agreement purposes. Tense is also 
raised to adjoin [AGRS] for licensing of nominative case. The verb [bala] is raised to [AGRO]. Finally the object is then raised covertly to the specifier position of [AGRO]. The verb, together with [AGRO], licenses the NP object's accusative case. If the object clitic is present, which is possible in Sesotho, the object will be raised overtly before spell out. After all the categories have been raised, the structure will be as in (2) below:

Diagram 2. Sesotho transitive sentence after movement

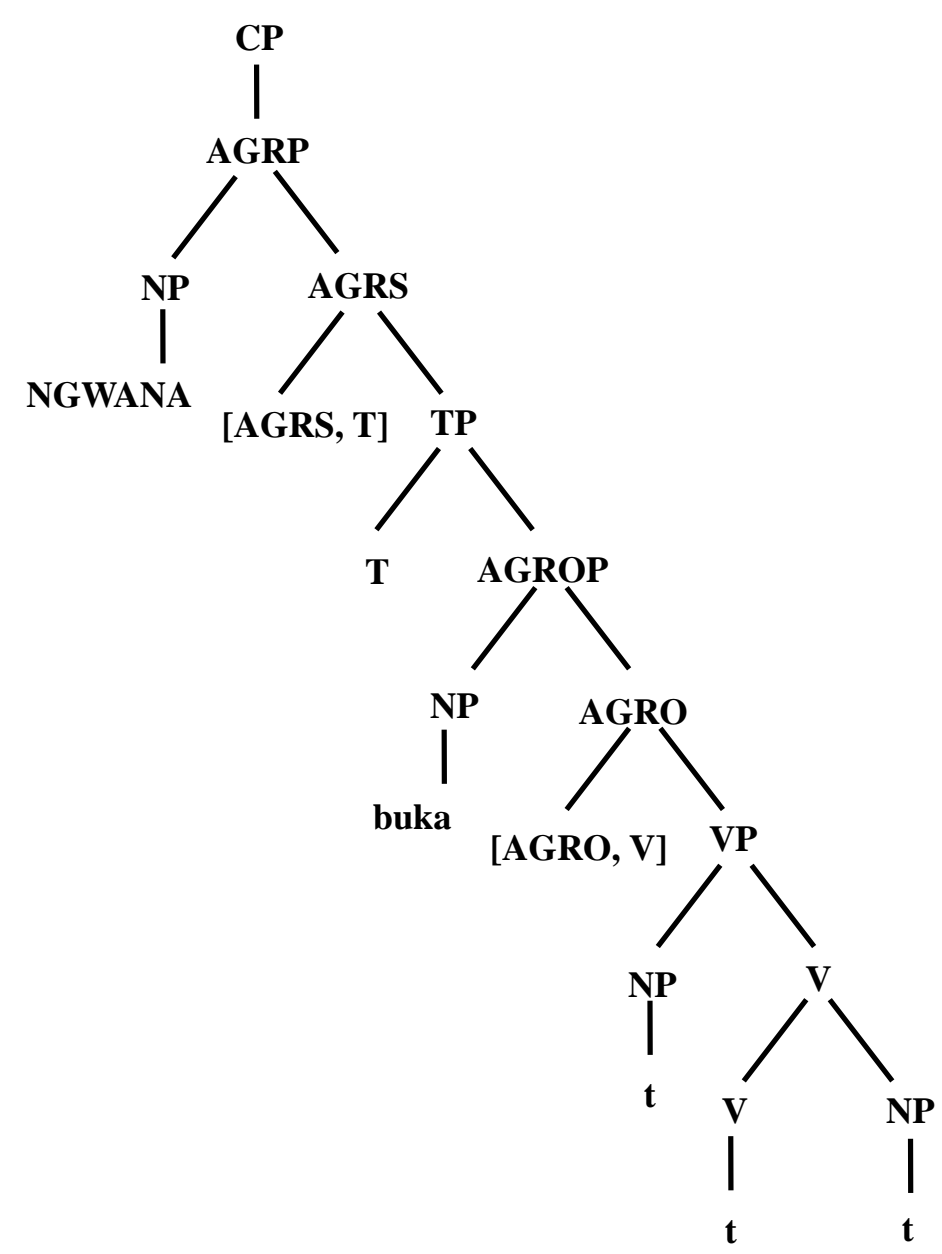

\section{The object in Sesotho}

Sesotho is a SVO language where the object always follows the verb. It has both direct objects and indirect objects which may appear as overt categories or as null objects in the sentence.

2.1 Overt objects 
Overt objects are lexical NP objects which are phonologically represented in post verbal positions. As nominals, objects in Sesotho appear with nominal modifiers and they are closely associated with verbs. It will therefore be proper to deal with them in relation to various kinds of verbs, such as intransitive, monotransitive and ditransitive verbs.

2.1.1 Intransitive verbs

While objects normally appear with transitive verbs, in Sesotho there are certain NP objects which appear with intransitive verbs as non-arguments. Such NP's, according to Du Plessis and Visser (1995), are cognate objects and idiomatic objects. Cognate objects may be non-argument NP's which are referred to as adjuncts:

(3) $\mathrm{Ke}$-nyetse [sethepu]

I married polygamous marriage

[ I married in polygamous marriage ]

There are however cognate objects which are full arguments as indicated by a sentence in (4) below:
(4) $\mathrm{Ka}$ lora [toro]
I dreamt a dream
[ I dreamt a dream ]

With regard to idiomatic objects, Du Plessis and Visser (1995) state that there are also intransitive verbs which appear with adjunct phrases that give rise to idiosyncratic meaning. These verb phrases are usually found in idiomatic expressions as in (5) below:

(5) Ke tswile [kotsi]

$$
\text { I got injury }
$$

[ I got injured ]

\subsubsection{Transitive verbs}

According to Du Plessis and Visser (1995), transitive verbs subcategorize for one internal argument which is a direct object. These NP objects may have theta roles of patient, theme or experiencer:

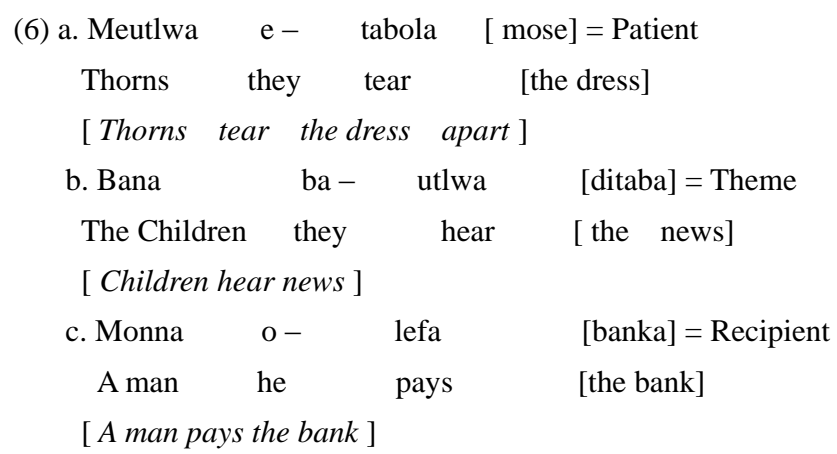

Du Plessis and Visser (1995) identify various types of objects in Sesotho: 


\section{Negation of the Object in Sesotho}

a) Coordinated Objects

$\begin{array}{ccccc}\text { (7) } \mathrm{Ke} & - \text { batla } & \text { [bohobe } & \text { le } & \text { nama] } \\ \text { I } & \text { want } & \text { [ bread } & \text { and } & \text { meat] } \\ \text { [ I want bread and meat ] }\end{array}$

b) NP Locative Objects

According to Du Plessis and Visser (1995) locative NP's cannot appear as objects of the verb in Sesotho but as adjuncts in the object position:
(8) $\mathrm{Ke}-\mathrm{a}-$ tseba [Kapa]
I know [Cape Town]
[ I definitely know Cape Town ]

c) Sentential Pronoun as Objects
(9) Bana ba - entse [hoo] hobane ba lapa
The children they done [that] because they hungry
[ Children have done that because they are hungry]

d) Ideophone Objects

(10) $\mathrm{O}$ itse tjhwabo
She/he said snatch
[ He snatched the kierie ]

\subsubsection{Ditransitive verbs}

According to Du Plessis and Visser (1995), ditransitive verbs subcategorize for two internal arguments viz. the indirect object and the direct object. According to Ramone (1992), these two objects are grammatically and semantically dissimilar. Structurally they both occur after the verb, i.e. one immediately after the verb and the other in the position further away from the verb.

a) Direct Objects

According to Ramone (1992), in double object constructions, direct objects appear on the periphery of the sentence and they mostly have the semantic interpretation of theme:

$\begin{array}{lllll}\text { (11) Monna o } & \text { adima mora } & \text { [pere] } \\ \text { A man he lends son } & \text { [horse] } \\ \text { [ A man lends the son a horse] } & \end{array}$

b) Indirect Objects

Mokete (1997) states that indirect NP objects with the feature [+ human] always appear adjacent to the verb carrying either the meaning of beneficiary, recipient or malefective:
(12) Mosadi o fa [ngwana] kobo
Woman she gives [child] blanket
[ A woman gives a child a blanket ]

c) Applied objects 


\section{Elias Nyefolo Malete}

Ramone (1992) describes applied object as the extra argument of the applied form of the verb. The applied object is dependent on the affix [- el -]. It is adjacent to the verb and has theta roles of beneficiary, purpose or cause:

$$
\begin{aligned}
& \begin{array}{ccccc}
\text { (13) a. Mme } & o- & \text { kopela } & {[\text { ngwana }} & \text { bohobe } \\
\text { Mother } & \text { she } & \text { asks } & \text { [ child] } & \text { bread }
\end{array} \\
& \text { [Mother asks for bread for the child] } \\
& \begin{array}{cccccc}
\text { b. Mme } & \mathrm{o}- & \text { phehela } & \text { [ngwana] } & \text { dijo }= & \text { Beneficiary } \\
\text { Mother } & \text { she } & \text { cooks } & \text { [child] } & \text { food } &
\end{array} \\
& \text { [Mother cooks food for the child] }
\end{aligned}
$$

d) The Null object

According to Du Plessis and Visser (1995) objectival concords occur as prefixes of the verb in morphology without lexical NP objects. In such cases the objects are referred to as null or empty NP objects and they are represented phonologically by empty pronominals indicated as [pro]. Idiophones can also appear with an empty [pro]. The sentences in (14) with the diagram in (3) will illustrate:

$$
\begin{array}{ccccc}
\text { (14) Mosadi } & \mathrm{o}- & \mathrm{mo}_{\mathrm{i}}- & \text { hladile } & \text { [pro] } \\
\text { The woman } & \text { she } & \text { him } & \text { divorced } & \text { [pro] }
\end{array}
$$

[ The woman divorced him ]

\section{Diagram 3. The null object}

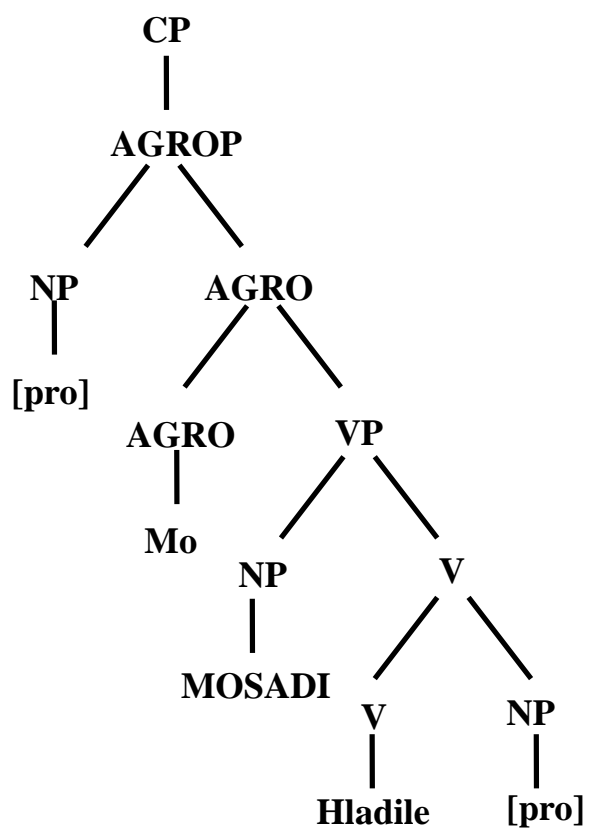




\section{Negation of the Object in Sesotho}

\subsection{Properties of Sesotho objects}

Du Plessis and Visser (1995) state that there are three obvious Sesotho object properties. In terms of the word order, Sesotho is an SVO language as the sentence in (15) will indicate:

\begin{tabular}{|c|c|c|c|}
\hline (15) [Ngwana] & {$[0-$} & batla] & [dipompong] \\
\hline Child & she/he & wants & sweets \\
\hline $\mathrm{s}$ & & $\mathrm{v}$ & o \\
\hline
\end{tabular}

In transitive verbs the objectival agreement may appear on the verb:

(16) $\mathrm{Re}-\mathrm{ka}-\mathrm{mo}_{\mathrm{i}}$ - bona [morwetsana ${ }_{\mathrm{i}}$ ]

We can her see the girl

[ We can see her, the girl]

The objectival agreement may also be found with ditransitive verbs:

(17) $\mathrm{Ke}-\mathrm{ba}_{\mathrm{i}}$ - ruta Sesotho [bana $\left.\mathrm{i}_{\mathrm{i}}\right]$

I them teach Sesotho children

[ I teach them Sesotho, the children ]

In passive sentences, the object may be moved to the subject position as indicated in (18) below:

(18) [Batho bana $\quad$ ba $-\quad a-$ bitswa
People these them
[ These people are being called ]

\section{Negation of the object with non-copulative verbs}

Negation of the object argument will be considered within transitive and ditransitive verbs. Three possible ways of negating the NP object will be examined, viz. negation of the object in postverbal position, negation of the object by cleft sentences and negation of the object by sentences with the locative AGRS [Ho].

\subsection{Postverbal negation}

As indicated above, the object argument may be negated in its original postverbal position in transitive constructions.

\subsubsection{Transitive verbs}

The object argument with feature animacy, which is to be negated, is indicated in (19) below:

(19) Mosuwe o- shapa [bana]
Teacher she/he beats children
[The teacher beats the children ]

In (19) above, the object argument appears next to the verb and it is not moved. To 


\section{Elias Nyefolo Malete}

establish negation of such an NP object, the negative morpheme [ha] is employed and it will appear with the negative suffix [- e.]. A contrastive clause is also necessary to highlight negation of the object as shown in (20) below:

(20) Mosuwe ha $-\mathrm{a}-$ shape [bana], $[0-$ shapa ditlokotsebe]
Teacher not she/he beat children, she/he beats delinquents
[ The teacher doesn't beat children, she/he beats delinquents ]

In (20), the object argument is negated within the verb phrase as the objects form part of the transitive verb, i.e. the negation of the verb also affects its arguments, which in this case is the objects [bana].

\subsubsection{Ditransitive verbs}

As in the case of transitive verbs, the object arguments i.e. direct and indirect objects, may be negated in their original postverbal position in ditransitive constructions. The object arguments to be negated are indicated in the sentences in (21) below:

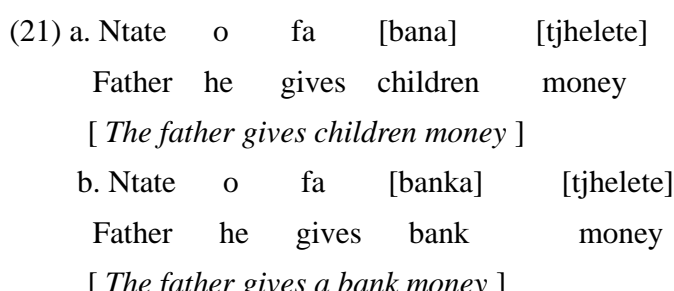

In (21) above, the indirect object [bana] is animate and the indirect object [banka] is inanimate. In both (21.a,b) the direct object is inanimate. To negate the objects above, the negative morpheme [ha] is employed and will appear with the negative suffix [- e]:

\begin{tabular}{|c|c|c|c|c|}
\hline $\begin{array}{c}\text { (22) a. Ntate } \\
\text { Father }\end{array}$ & $\begin{array}{l}\text { ha }- \\
\text { not }\end{array}$ & $\begin{array}{l}\mathrm{a}- \\
\text { he }\end{array}$ & $\begin{array}{l}\mathrm{f}-\mathrm{e} \\
\text { gives }\end{array}$ & $\begin{array}{l}\text { [bana] } \\
\text { children }\end{array}$ \\
\hline
\end{tabular}

[ The father doesn't give children money]

$\begin{array}{cccccl}\text { b. Ntate } & \text { ha }- & \text { a }- & \text { f- e } & \text { [banka] } & \text { [tjhelete] } \\ \text { Father } & \text { not } & \text { he } & \text { gives } & \text { bank } & \text { money }\end{array}$

[The father doesn't give the bank money]

In (22) above, the indirect and the direct objects are negated within the verb phrase as they are subcategorized by a ditransitive verb. To isolate negation on these objects, a contrasting clause is necessary either to put emphasis on the direct or the indirect object. To negate the indirect animate object [bana], a contrasting clause with an animate NP will be employed as indicated in (23) below:

$$
\begin{aligned}
& \text { (23) Ntate ha }-\mathrm{a}-\mathrm{f}-\mathrm{e} \quad \text { [bana] tjhelete, }[\mathrm{o}-\mathrm{fa}-\text { mme }] \\
& \text { Father not he gives children money, he gives mother }
\end{aligned}
$$

[ Father doesn't give children money, he gives it to the mother]

In this way as in (23) above, only the indirect object is negated. To negate the direct 


\section{Negation of the Object in Sesotho}

object [tjhelete], a contrasting clause with the features [- human] and [- animate] will be employed:

$$
\begin{aligned}
& \text { (24) Ntate ha }-\mathrm{a}-\mathrm{f}-\mathrm{e} \text { bana [tjhelete], }[\mathrm{o}-\text { ba }- \text { fa dijo] } \\
& \text { Father not he gives children money, he them gives food } \\
& \text { [ The father doesn't give children money, he gives them food] }
\end{aligned}
$$

In the case where the indirect object is not human, a contrasting clause will also be non-human as illustrated in (25):

$$
\begin{aligned}
& \text { (25) Ntate ha }-\mathrm{a}-\mathrm{f}-\mathrm{e} \text { [banka] tjhelete, }[\mathrm{o}-\mathrm{fa} \text { kereke] } \\
& \text { Father not he gives bank money, he gives church } \\
& \text { [ The father doesn't give a bank money, he gives to the church ] }
\end{aligned}
$$

From the above sentences, one may conclude that both indirect and direct objects are negated within a verbal complex. The indirect object is mostly affected by negation whereas the direct object as [theme] is less affected. To isolate them in negation, a contrasting clause plays an important role in determining which one is negated.

\subsection{NP object negation with cleft sentence}

\subsubsection{Transitive Verbs}

The object argument may be moved to the subject position through clefting, where it will be introduced by the copula [ke]:

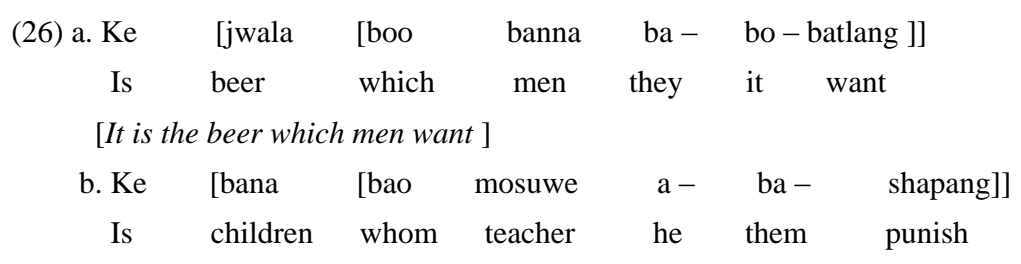

[ It is the children whom the teacher punishes ]

To establish negation of the object arguments, the negative morpheme [ha] and the negative copulative verb [se] will be made to appear with the NP object with clausal modifier:

$$
\begin{aligned}
& \text { (27) a. } \mathrm{Ha}-\mathrm{se} \text { [jwala [boo banna ba }- \text { bo }- \text { batlang] } \\
& \text { Not is beer which men they it want } \\
& \text { [ It is not beer which men want] } \\
& \text { b. } \mathrm{Ha}-\mathrm{se} \text { [bana [bao mosuwe a }- \text { ba }- \text { shapang]] } \\
& \text { Not is children whon teacher he them punish }
\end{aligned}
$$

It is also necessary to put the above sentences in (27) in context by adding a contrasting clause in order to strengthen negation of the object:

$$
\begin{array}{rlrlll}
\text { (28) a. Ha }- \text { se } & \text { jwala boo banna ba }- \text { bo }- & \text { batlang], [ke } & \text { senomaphodi] } \\
\text { Not is } & \text { beer which men they it } & \text { want, is cold drink }
\end{array}
$$




\section{Elias Nyefolo Malete}

[ It is not beer which men want, it is the cold drink]

b. $\mathrm{Ha}$ - se [bana bao mosuwe a - ba - shapang], [ke ditlokotsebe]

Not is children whom teacher he them punish, is delinquents

[ It is not children whom the teacher is punishing, it is delinquents ]

From the sentences in (27) and (28), one may deduce that it is possible to use cleft sentences in negating the object arguments with featured animacy.

\subsubsection{Ditransitive Verbs}

The object argument may be moved to the sentence's initial position through clefting. In the case of ditransitive constructions, only the moved NP object will be negated. In (29) below, the indirect object is moved to appear in a focus position:

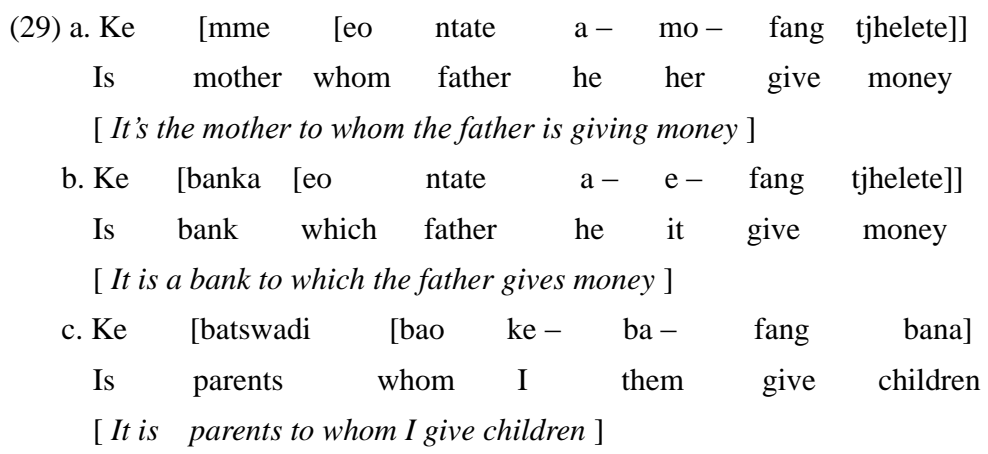

To establish negation of the moved indirect object, the negative morpheme [ha] and the negative copulative verb [se] are employed as in (30) below:

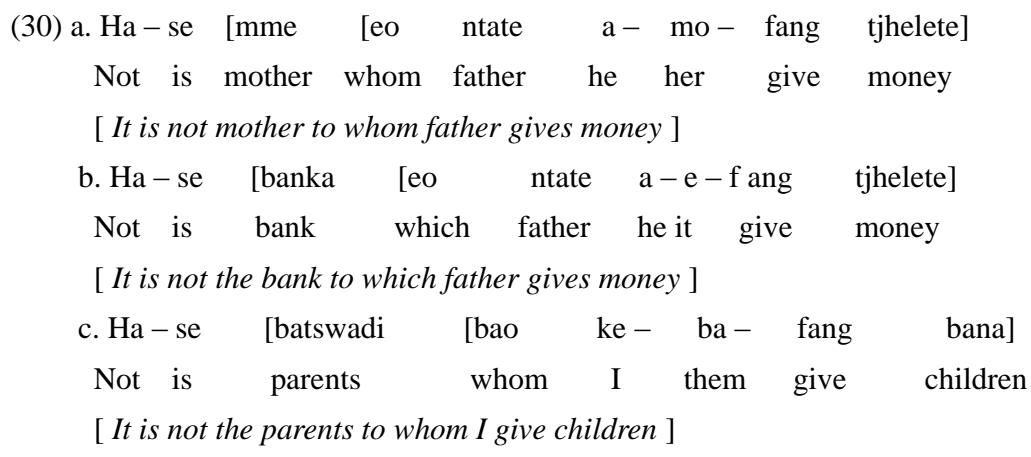

To strengthen negation on the moved indirect object, it is also acceptable to add a contrasting clause as illustrated in (31) below:

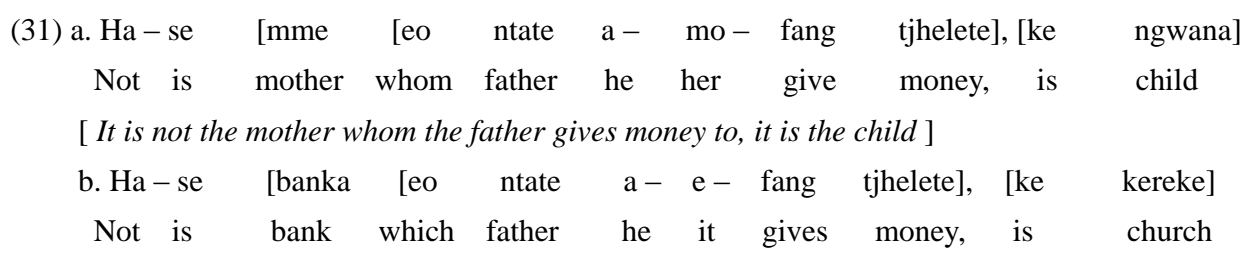




\section{Negation of the Object in Sesotho}

[ It is not the bank which the father gives money to, it is the church ]
c. Ha-se [batswadi [bao ke- ba - fang bana], [ke mesuwe]
Not is parents whom I them giver children, is teachers

[ It is not the parents whom I give children to, it is the teachers ]

When the animate direct object is moved to appear in a focus position, the sentence becomes ambiguous as in (32) below:

$\begin{array}{rllllll}\text { (32) } \mathrm{Ha}-\mathrm{se} & \text { [bana } & {[\text { bao }} & \mathrm{ke}- & \mathrm{ba}- & \text { fang } & \text { batswadi] } \\ \text { Not is } & \text { children } & \text { whom } & \mathrm{I} & \text { them } & \text { give } & \text { parents }\end{array}$

[ It is not children to whom I give parents] / [ It is not children whom I give to parents]

From the sentences in (31) and (32) above, it would seem that only indirect objects can appear in a focus position and therefore only indirect objects can be negated by means of cleft sentences in double object constructions.

\subsection{Object negation with the locative AGR [ho]}

\subsubsection{Transitive Verbs}

The object arguments with feature animacy may be moved to the sentence initial position where they are introduced by the locative AGRS [Ho] with the copulative verb [LI] and [na]:

$$
\begin{aligned}
& \text { (33) a. }\left[\mathrm{pro}_{\mathrm{i}}\right], \mathrm{Ho}_{\mathrm{i}} \text { [jwala boo banna ba }- \text { bo }- \text { batlang] } \\
& \text { There is beer which men they it want } \\
& \text { [There is beer which men want ] } \\
& \text { b. }\left[\mathrm{pro}_{\mathrm{i}}\right], \mathrm{Ho}_{\mathrm{i}} \text { [bana bao mosuwe a- ba- shapang] } \\
& \text { There are children whom teacher he them punish } \\
& \text { [ There are children whom the teacher is punishing ] } \\
& \text { c. }\left[\mathrm{pro}_{\mathrm{i}}\right], \mathrm{Ho}_{\mathrm{i}} \text { na } \quad \text { le } \quad \text { jwala boo banna ba - bo-batlang] } \\
& \text { [ There is beer which men want ] } \\
& \text { d. }\left[\mathrm{pro}_{\mathrm{i}}\right], \mathrm{Ho}_{\mathrm{i}} \text { na le [bana bao mosuwe a }- \text { ba }- \text { shapang] } \\
& \text { There exist with children whom teacher he them punish } \\
& \text { [ There are children whom the teacher is punishing ] }
\end{aligned}
$$

In establishing negation of the objects in (33) above, the negative morpheme [ha] will appear with the locative AGRS [Ho] with the NP objects as heads of the relative clause:

$$
\begin{aligned}
& \text { (34) a. }\left[\mathrm{pro}_{i}\right] \text {, Ha- ho } \mathrm{Ho}_{\mathrm{i}} \text { [jwala boo banna ba }- \text { bo }- \text { batlang] } \\
& \text { [ There is no beer which men want] } \\
& \text { b. }\left[\mathrm{pro}_{\mathrm{i}}\right], \mathrm{Ha}-\mathrm{ho}_{\mathrm{i}} \text { [bana bao mosuwe a }- \text { ba }- \text { shapang] } \\
& \text { Not there children whom teacher he them punish }
\end{aligned}
$$

[ There are no children whom the teacher is punishing ] 


\section{Elias Nyefolo Malete}

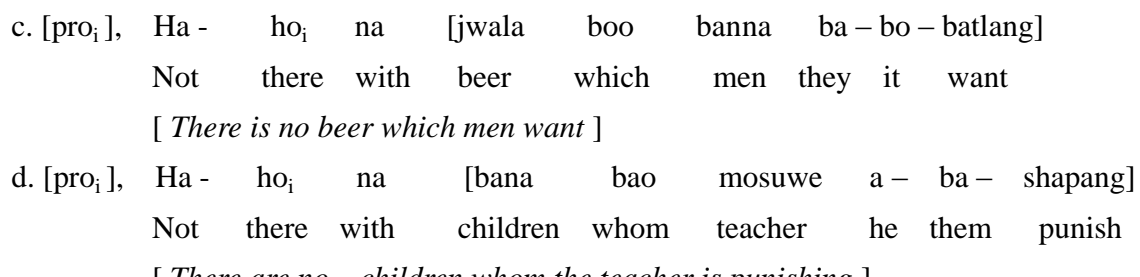

To strengthen negation of the object argument, a contrasting clause is added as indicated in (35) below:

$$
\begin{aligned}
& \text { (35) a. Ha ho [jwala boo banna ba-bo-batlang], [ ke senomaphodi] } \\
& \text { Not there beer which men they it want, is cold drink } \\
& \text { [ There is no beer which men want, there is the colddrink] } \\
& \text { b. Ha - ho na [bana bao mosuwe a- ba-shapang [ke ditlokotsebe] } \\
& \text { Not there with children whom teacher he them punish is delinquents } \\
& \text { [ There are no children whom the teacher is punishing, there are delinquents ] }
\end{aligned}
$$

From the sentences in (34) and (35) above, one may conclude that it is also possible to negate the object arguments in transitive constructions by means of locative AGRS [Ho] clauses. The animate and inanimate NP objects may be negated by cleft sentences and sentences with locative AGRS [Ho], where the object is negated within a larger sentence scope. It is also possible to negate the NP object within the VP.

\subsubsection{Ditransitive Verbs}

It is possible for the indirect object argument to be moved to the sentence initial position where it will be introduced by the locative AGRS [Ho] with the copulative verbs [LI] and [na]. The direct object will then appear at the periphery of the sentence:

$$
\begin{aligned}
& \text { (36) a. }\left[\mathrm{pro}_{\mathrm{i}}\right], \mathrm{Ho}_{\mathrm{i}} \quad[\mathrm{mme} \text { [eo ntate a }-\mathrm{mo}-\text { fang tjhelete] } \\
& \text { There is mother whom father he her gives money } \\
& \text { [ There is the mother to whom the father is giving money] }
\end{aligned}
$$

b. $\left[\mathrm{pro}_{\mathrm{i}}\right], \mathrm{Ho}_{\mathrm{i}}$ [banka $[\mathrm{eo}$ ntate a $-\mathrm{e}-$ fang tjhelete]
There is bank which father he her gives money
[ There is a bank to which the father is giving money ]

$$
\begin{aligned}
& \text { c. }\left[\mathrm{pro}_{\mathrm{i}}\right], \mathrm{Ho}_{\mathrm{i}} \text { na le }[\mathrm{mme} \quad[\mathrm{eo} \text { ntate } \mathrm{a}-\mathrm{mo}-\text { fang tjhelete]] } \\
& \text { There exist with mother whom father he her gives money } \\
& \text { [ There is the mother to whom father is giving money ] }
\end{aligned}
$$

d. $\left[\mathrm{pro}_{\mathrm{i}}\right], \mathrm{Ho}_{\mathrm{i}}$ na le [banka [eo ntate a $-\mathrm{e}-$ fang tjhelete]

There exist with bank which father he her gives money

[ There is a bank to which father is giving money ]

In negating the object argument, the negative morpheme [ha] will appear with the locative AGRS [Ho] with the object as the head of the relative clause. In the case of the 


\section{Negation of the Object in Sesotho}

copulative verb [na], the preposition [le] disappears as demonstrated by the sentences in (37) below:

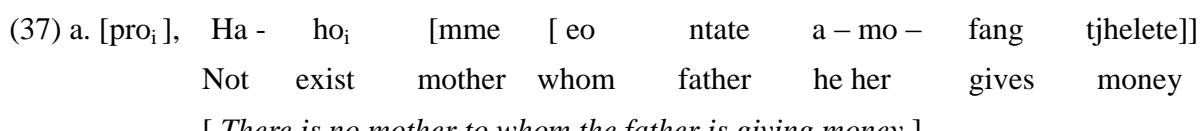

[ There is no mother to whom the father is giving money ] $\begin{array}{rllllllll}\text { b. }\left[\mathrm{pro}_{\mathrm{i}}\right], & \mathrm{Ha}-\mathrm{ho}_{\mathrm{i}} & {[\text { banka }} & {[\mathrm{eo}} & \text { ntate } & \mathrm{a}- & \mathrm{e}- & \text { fang } & \text { tjhelete }]] \\ \text { Not exist bank } & \text { which father he } & \text { it } & \text { gives } & \text { money }\end{array}$

[There is no bank to which the father is giving money]

c. $\left[\mathrm{pro}_{\mathrm{i}}\right], \mathrm{Ha}-\mathrm{ho}_{\mathrm{i}}$ na [mme [eo ntate a - mo- fang tjhelete]]

Not exist with mother whom father he her gives money

[There is no mother to whom the father is giving money]

d. $\left[\mathrm{pro}_{\mathrm{i}}\right]$, Ha - ho $\mathrm{i}_{\mathrm{i}}$ na [banka [eo ntate a- e - fang thelete]]

Not exist with bank which father he it gives money

[There is no bank to which the father is giving money]

A contrasting clause may be added to put focus on the indirect object as illustrated by the sentences in (38) below:

(38) a. Ha - ho [mme [eo ntate a-mo-fang tjhelete], [ke bana]
Not exist mother whom father he her gives money, is children
[There is no mother whom the fatherisgiving money to, there are the children ]
b. Ha - ho [banka [eo ntate a - e - fang tjhelete], [ke kereke]
Not exist bank which father he her gives money, is church

[There is no bank which the father is giving money to, there is the church ]

As in the case of cleft sentences, when the animate direct object is moved to appear in a focus position, the sentence becomes ambiguous as in (39) below:

(39) $\mathrm{Ha}-$ ho [ bana [bao ke - ba - fang batswadi]

Not exist children whom I them give parents

[There are no children who I give to parents] / [There are no children to whom I give the parents]

From the sentences in (37) and (38) above, it would seem that only indirect objects may appear in a focus position and as a result, only indirect objects may be negated by clauses with locative AGRS [Ho]. The direct and the indirect objects can be negated within the verbal complex, where they are both affected by the ditransitive verb. In the case of cleft sentences and clauses with locative AGRS [Ho], only the moved NP object is negated and in both constructions only the indirect object appears in the focus position.

\section{Summary}

This paper examined whether it is possible to use clauses to achieve constituent negation, and in this regard the NP object as Sesotho does not have a direct means of negating 
constituents within sentence constructions. The paper also examined object negation in non copulative verbs within transitive and ditransitive verb constructions. The following conclusions can be made.

Sesotho has no direct means of negating clausal constituents, but employs negative clauses such as cleft sentences, clauses with the locative morpheme /ho/ and clauses with subject inversion. In order to negate a single clausal constituent, Sesotho follows a route comprising of three steps. Firstly, the constituent to be negated, in this case the NP object, needs to be placed in focus position by means of copulative verbs, the locative morpheme /ho/ or the existential /ho/. The second step is characterized by implementing negative morphemes /ha/ and /se/ to effect negation. In this step, the object argument is negated within the larger scope resulting in sentential negation. In the last step, contrastive clauses are employed. In other words, constituents are negated in context.

In terms of Haegeman's (1995) Neg-Criterion, this study intends to suggest that Sesotho does not have non-negative operators that will constitute local negation. It conforms to the Neg-Criterion in terms of negative operators which trigger subject inversion, in that it is only after sentential negation has occurred that local negation is achieved through contrastive negation. This is because Sesotho negative morphemes, in this case /ha/ and /se/, are bound negative morphemes. They are verbal prefixes which always appear with their verb stems. In order to negate a clausal constituent, these negative morphemes have to move with their verb stems, hence negative clauses are employed. As verbal prefixes, they cannot be generated from nouns and adverbs as it is the case with English. It is for this reason that Sesotho does not have direct means of negating clausal constituents.

Furthermore, post-verbal negation is possible in transitive verbs where the object arguments are negated within the verb phrase because NP objects form part of the transitive verb. i.e. the negation of the verb also affects its arguments, which in this case are the objects [jwala] and [bana] in constructions like:

(40) a. Ha se [jwala [boo banna ba bo batlang]]
Not is beer which men they it want
[It is not the beer which men want]
b. Ha se [bana [bao mosuwe a ba shaping]]
Not is children whom teacher he them punish
[ It is not the children whom the teacher punishes ]

Post verbal negation is also possible in ditransitive verbs where both indirect and direct objects are negated within the verbal complex. The indirect object is mostly affected by negation, whereas the direct NP object as [theme] is less affected. To achieve constituent negation, Sesotho needs to employ contrasting clauses:
(41) Ntate
ha $-\mathrm{a}-\mathrm{fe}$
[bana]
tjhelete, $[\mathrm{o}-\mathrm{fa}-$
mme] 


\section{Negation of the Object in Sesotho}

\section{Father not he gives children money, he gives mother \\ [ Father doesn't give children money, he gives it to the mother ]}

Preverbal negation is possible in Sesotho in order to achieve constituent negation. This is possible by using the cleft sentences in both transitive and ditransitive verbs. However, it would seem that with ditransitive verbs, only indirect objects can appear in a focus position, and subsequently only indirect objects can be negated by means of cleft sentences. As it is the case with post verbal negation, contrastive clauses are also necessary to achieve constituent negation:

$\begin{array}{rllrrrrr}\text { (42) } \mathrm{Ha} & \text { se } & \text { [mme } & \text { [eo ntate a mo fang tjhelete], ke bana } \\ \text { Not } & \text { is mother whom father he } & \text { her gives money, is children }\end{array}$

[ It is not the mother whom the father gives money to, it is the children ]

Pre verbal negation is also possible in Sesotho by using clauses with locative AGRS [ho] in both transitive and ditransitive verbs. As it is the case with cleft sentences, only indirect NP objects may be negated by clauses with locative AGRS [Ho].

\section{References}

Anderson, JM. 1984. Objecthood . In Plank F. (ed). Towards a Theory of Grammatical Relations. London : Academic Press.

Collinge, N.E. 1984. How to discover Direct Objects. In Plank F, (ed) : Towards a Theory of Grammatical London : Relations. Academic Press.

Du Plessis, J.A. \& Visser, M.W. 1992. Xhosa Syntax. Pretoria : Via Afrika.

Du Plessis, J.A. \& Visser, M.W. 1995. Sesotho Syntax Stellenbosch Communications in African Languages, No. 3. University of Stellenbosch.

Du Plessis, J.A. 1997. Morphology of the African Languages. Stellenbosch Communications in African Languages. No. 6. University of Stellenbosch.

Gil, D. 1984. On the notion of Direct object in Patient Prominent Languages. In Plank, F. (ed). Towards a Theory of Grammatical Relations. London : Academic Press.

Haegeman. LMV. 1995. The Syntax of Negation. Cambridge : Cambridge University Press.

Haegeman, L. 1997. Elements of Grammar. In Haegeman (ed) : Elements of Grammar: Handbook in Generative Syntax. Netherlands : Kluwer Academic Publishers.

Klima, J. 1964. Negation in English. In J Fodor and Katz (eds) : The structure of Language. N Jersey: Prentice - Hall 246 - 32.

Laka, I. 1994. On the Syntax of Negation. New York, Garland Publishres.

Lazard,G. 1984. Actance variations and categories of the object. In Plank F,(ed) : Towards a Theory of Grammatical Relations. London : Academic Press.

Mokete, CM. 1997. Verbs with Predicate Complements in Sesotho. Unpublished MA Thesis. University of Stellenbosch.

Moravcsik.E.A. 1984. The place of direct objects among the Noun Phrase Constituents of Hangarian. In Plank F, (ed) : Towards a Theory of Grammatical relations. London : Academic Press.

Ramone, PM. 1992. Ditransitive Applied Verbs in Southern Sotho. Unpublished MA Thesis. University of Stellenbosch.

Ouhalla, J.1999. Introducing Transformational Grammar: From Principles and Parameters to minimalism. London. Oxford University Press

Zanuttini, R. 1997.Negation and Clausal Structure. A Comparative Study of Romance Languages. Oxford : Oxford University Press. 